Revue d'histoire de l'Amérique française

ZAS REVUE D.HISTOIRE DE L'AMÉRIQUE FRANÇAISE

\title{
Où repose Pierre Gauthier de la Vérendrye ?
}

\section{Olivier Maurault}

Volume 6, numéro 4, mars 1953

URI : https://id.erudit.org/iderudit/301547ar

DOI : https://doi.org/10.7202/301547ar

Aller au sommaire du numéro

Éditeur(s)

Institut d'histoire de l'Amérique française

ISSN

0035-2357 (imprimé)

1492-1383 (numérique)

Découvrir la revue

Citer cet article

Maurault, O. (1953). Où repose Pierre Gauthier de la Vérendrye ? Revue d'histoire de l'Amérique française, 6(4), 467-469.

https://doi.org/10.7202/301547ar d'utilisation que vous pouvez consulter en ligne.

https://apropos.erudit.org/fr/usagers/politique-dutilisation/ 


\section{OÜ REPOSE \\ PIERRE GAUTHIER DE LA VÉRENDRYE?}

Dans le jardin public de Saint-Boniface, face au grand hôpital et à la Rivière Rouge, se dresse un splendide monument par le sculpteur Emile Brunet.

Trois personnages, à demi superposés, composent ce monument; ils sont tous les trois résolument tournés vers l'Ouest: La Vérendrye, au premier plan, la jambe droite levée sur une roche, dans la position de la marche; à son côté, un missionnaire debout, portant la croix dans sa main droite; devant lui, un Indien, agenouillé, la main en abat-jour sur ses yeux, scrutant l'horizon. Groupe plastique, vivant et plein de sens, dont le bronze se détache nettement sur une large stèle de marbre pâle. La base s'étend de chaque côté, portant une frise délicate, représentant, à gauche, les animaux à fourrure et, à droite, un élévateur à grain, un canot d'écorce et des armes: en somme, un résumé des ressources et de l'histoire de l'Ouest canadien. Devant le groupe se lit, sous le nom de La Vérendrye, une inscription latine: "Istas invenit terras easque humanitati fidei aperuit 1748-1948". Ce qui signifie: La Vérendrye découvrit ces terres et les ouvrit à l'humanité et à la foi."

J'assistais à la cérémonie de dévoilement de ce monument, en 1938. Avant d'entreprendre le voyage de Saint-Boniface, j'aurais voulu apporter à nos compatriotes du Manitoba quelques précisions nouvelles sur la sépulture de leur héros. Mes recherches étaient alors restees infructueuses.

On savait déjà que Gauthier de la Vérendrye avait été inhumé, le 7 décembre 1749, sous la chapelle de Sainte-Anne de l'ancienne église Notre-Dame de Montréal. On savait aussi que cette chapelle occupait le soubassement entre la tour de l'église et le transept, c'est-à-dire l'endroit précis de la Place d'Armes où, de nos jours, stationnent les taxis...

Mais, des dépouilles de tant de Montréalais enterrés sous l'église, qu'avait-on fait, quand celle-ci fut démolie, après 1829, pour dégager 
la façade de la nouvelle Notre-Dame, ou quand fut rasé le vieux clocher en 1843 ? Ce sont ces deux points qu'il fallait élucider.

Aux deux dates précitées, 1829 et 1843 , le cimetière de Montréal se trouvait au Mont Saint-Antoine, c'est-à-dire au sud de la rue Dorchester, où s'étend maintenant une moitié du square Dominion et où s'élève la Basilique-cathédrale. C'e cimetière, inauguré en 1799, fut fermé en 1855.

Y avait-on transporté les restes des Montréalais inhumés dans les trois anciens cimetières et sous l'église Notre-Dame, l'ancienne?

Pour les cimetières de la rue Saint-Jacques, on peut répondre nettement: en 1825, 54 "voyages" d'ossements qui y furent recueillis, prirent le chemin du cimetière Saint-Antoine.

Le sort des ossements provenant de l'ancienne église fut différent. On estimait, en 1830, que 730 corps avaient été enterrés dans la crypte de ce vénérable temple, sans compter ceux qui reposaient sous le chœur. Or, le 26 février de cette même année, il est décidé d'exhumer les corps enterrés sous l'église, qu'on allait bientôt démolir, pour les transporter ailleurs. Où? Nous allons le savoir en consultant un autre document: la liste des inhumations faites dans la nouvelle église Notre-Dame, de 1829 à 1840 . Nous avons les noms de 102 montréalistes enterrés dans la cave de l'église, le long du mur donnant sur le jardin du Séminaire, sous la chapelle du Rosaire: cette liste ne contient pas le nom de O'Donnell, l'architecte de l'église, qui est enterré au pied d'un pilier de l'église, ni ceux des Sulpiciens, des Sœurs de la Congrégation de Notre-Dame et des Frères des Ecoles Chrétiennes, qui reposaient sous le sanctuaire.

Mais dans cette précieuse liste, nous lisons les deux lignes que voici: "deux grandes fosses contenant les ossements des corps exhumés de la vieille église", et ces fosses sont placées justement entre les sépultures de l'hiver de 1830 et celles de l'automne 1831 .

De plus, on ne voit pas pourquoi les dépouilles inhumées sous la tour, n'auraient pas été transportées comme les autres, même s'il avait été réglé que la tour avec ses cloches resterait debout jusqu'à ce que les deux clochers de la nouvelle église soient construits ce qui advint en 1840 et 1843.

Ainsi donc, en l'absence de tout document qui attesterait que la dépouille de La Vérendrye ait été l'objet de recherches ou de soins particuliers, ou qui signalerait un dernier transport des osse- 
ments inhumés dans ces deux grandes fosses, il est à peu près certain que les cendres de Pierre Gauthier, sieur de La Vérendrye, chevalier de l'Ordre militaire de Saint-Louis, mêlées à celles de plusieurs centaines de nos ancêtres, reposent toujours dans la crypte de notre vénérable "Paroisse", ajoutant encore plus de prix à ce sanctuaire vraiment national.

Olivier Maurault, p.s.s. P.A. Président de la Societé historique de Montréal.

N.B. - Avec cette livraison de mars de la REVUE, votre abonnement prend fin pour l'année 1952-1953. Vous vous ferez, sans doute, un devoir de le renouveler le plus tôt possible. - Ne pas oublier que le prix du réabonnement est $\$ 5.00$. 